\title{
ВЛИЯНИЕ АТОМОВ ЭРБИЯ, ЛАНТАНА И РОСТОВЫХ ПРИМЕСЕЙ НА ЭФФЕКТИВНОСТЬ ОБРАЗОВАНИЯ РАДИАЦИОННЫХ ДЕФЕКТОВ В КРЕМНИИ
}

\author{
Ш.Х. Далиев, А.Т. Мамадалимов, М.Б. Бекмуратов \\ НИИ физики полупроводников и микроэлектроники НУ РУз, Ташкент, Узбекистан \\ shakhrukhd@mail.ru \\ (Получена 13.06.2019)
}

\begin{abstract}
Чуқур сатхплар ностационар сиғимли спектроскопияси усули ёрдамида эрбий, лантан ва кислород киришмаларининг кремнийда радиациявий нуқ̨сонларнинг хчосил бўлиш жараёнларига таъсири ўрганилган. Кремнийда эрбий ёки лантан киришмалари мавжудлиги радиациявий нуқссонларнинг хєосил бўлиш самарадорлигининг камайишига олиб келиши аникеланган. Эрбий ёки лантан билан легирланган ва ${ }^{60}$ Со $\gamma$-квантлар билан нурлантирилган кремнийда $A$ - ва $E$-марказларнинг концентрацияси назорат намуналарга нисбатан 4-5 баровар камлиги кўрсатилган. Радиациявий нукссонларнинг хєосил бўлиш самарадорлиги кремнийдаги кислороднинг мик̨дорига хєам боғликчлиги аникеланган.
\end{abstract}

\begin{abstract}
Методами нестационарной емкостной спектроскопии изучено влияние примесей эрбия, лантана и кислорода на процессы образования радиационных дефектов в кремнии. Установлено, что присутствие в $\mathrm{Si}$ примеси эрбия или лантана приводит к снижению эффективности образования радиационных дефектов. Показано, что концентрации как $A$-центров, так и $E$-центров в 4-5 раз меньше в $n$ - $\mathrm{Si}<\mathrm{Er}>$ или $n$-Si $<\mathrm{La}>$, облученном $\gamma$-квантами ${ }^{60} \mathrm{Co}$ по сравнению с контрольными облученными образцами. Обнаружено, что эффективность образования радиационных дефектов зависит и от содержания кислорода в кремнии.
\end{abstract}

The influence of the impurity of erbium, lanthanum and oxygen on the processes of formation of radiation defects in silicon was studied by method of deep level transient spectroscopy. It is established that the presence of erbium or lanthanum impurities in Si leads to a decrease in the efficiency of formation of radiation defects. It is shown that the concentrations of both $A$-centers and $E$-centers are 4-5 times lower in $n$-Si<Er>or $n$-Si<La> irradiated with $\gamma$-quanta ${ }^{60} \mathrm{Co}$ compared to the control irradiated samples. It was found that the efficiency of the formation of radiation defects depends on the oxygen content in silicon.

Известно, что в кремнии, выращенном методом Чохральского, подвергнутом воздействию радиации, образуются различные кислородсодержащие радиационные дефекты в зависимости от примесного состава. Кроме того, наличие в объеме кремния примесей редкоземельных элементов (РЗЭ) приводит к повышению устойчивости его параметров к воздействию радиации [1-6].

Целью данной работы является исследование методами нестационарной емкостной спектроскопии глубоких уровней (DLTS) влияния атомов эрбия, лантана и содержания неконтролируемой ростовой примеси кислорода на эффективность образования радиационных дефектов (РД) в $\mathrm{Si}$, облученном $\gamma$-квантами ${ }^{60} \mathrm{Co}$. Для проведения емкостных измерений на исследуемых образцах изготавливали диодные структуры по известной методике [7-8]. Измерения и обработка спектров также детально описаны в работах [7-10].

В качестве исследуемых образцов выбран $n$ - $\mathrm{Si}$, легированный эрбием $(\mathrm{Er})$ или лантаном (La) в процессе выращивания из расплава, с исходным удельным 
сопротивлением $\rho=10-30$ Oм·см. Полную концентрацию атомов $\mathrm{Er}$ или La в объеме монокристаллического Si определяли методом нейтронно-активационного анализа. Она составила $2 \times 10^{15} \div 8 \times 10^{17} \mathrm{~cm}^{-3}$ от начала к концу слитка. Контрольными образцами служили образцы $n$-Si с одинаковым удельным сопротивлением $\rho$ и различным содержанием кислорода - так называемый кислородный $\mathrm{Si} \mathrm{c}$ концентрацией оптически активных атомов кислорода $N_{0}{ }^{\text {опт }}=7 \times 10^{17}-1.1 \times 10^{18} \mathrm{~cm}^{-3}$ и бескислородный $\mathrm{Si}$ с $N_{0}$ опт $\leq 10^{16} \mathrm{~cm}^{-3}$. Образцы облучали при комнатной температуре $\gamma$-квантами ${ }^{60}$ Со с интенсивностью потока $\sim 3.1 \times 10^{12} \mathrm{\kappa в} / \mathrm{cm}^{2} \mathrm{c}$.

До и после облучения $\gamma$-квантами ${ }^{60}$ Со измеряли спектры DLTS образцов $n-\mathrm{Si}<\mathrm{Er}>$ или $n-\mathrm{Si}<\mathrm{La}>$ и контрольных нелегированных образцов и определяли энергетический спектр образуемых глубоких уровней (ГУ). Отметим, что в этих образцах $N_{0}^{\text {опт }}$ составляет $2 \times 10^{16}-8 \times 10^{17} \mathrm{~cm}^{-3}$. Анализ спектров DLTS показывает, что введение примеси $\mathrm{Er}$ или $\mathrm{La}$ в $\mathrm{Si}$ в процессе выращивания из расплава не приводит к образованию каких-либо глубоких уровней в запрещенной зоне кремния, хотя по данным нейтронно-активационного анализа атомы эрбия и лантана присутствуют в объеме кремния в достаточно высокой концентрации $\left(2 \times 10^{15}-4 \times 10^{17} \mathrm{~cm}^{-3}\right)$.

Как видно из спектров DLTS, в кислородном кремнии в результате $\gamma$-облучения как в контрольных образцах $n$-Si, так и в образцах $n$ - $\mathrm{Si}<\mathrm{Er}>$ и $n$ - $\mathrm{Si}<\mathrm{La}>$ вводится новый уровень с энергией ионизации $E_{c}-0.17$ эВ и сечением захвата электронов $\sigma_{n}=1 \times 10^{-14} \mathrm{~cm}^{2}$ (рисунок, кривые 1 и 2). Значения параметров этого ГУ относятся к известным комплексам вакансия-кислород ( $A$-центры) [11]. Из анализа измеренных спектров следует, что присутствие примеси Er или La приводит к замедлению процесса радиационного дефектообразования: концентрация $A$-центра в образцах $n$ - $\mathrm{Si}<\mathrm{Er}>$ и $n$-Si<La>, в 4-5 раз меньше, чем в контрольных образцах. Причем, чем больше концентрация эрбия или лантана, тем меньше концентрация РД.

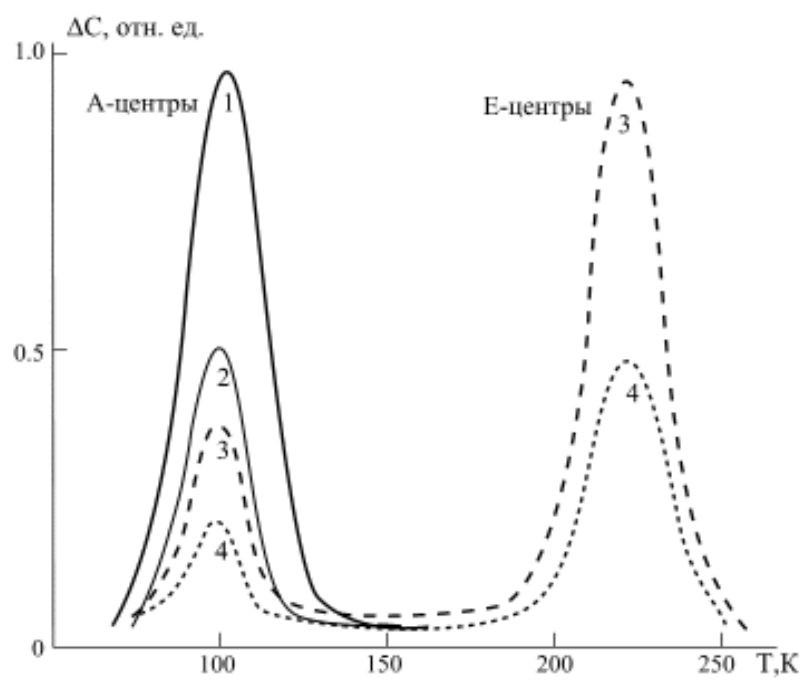

Рисунок.Спектры DLTS кислородного $n$ - $\mathrm{Si}(1)$ и $n$ - $\mathrm{Si}<\mathrm{Er}>(2)$ и бескислородного $n$ - $\mathrm{Si}$ (3) и $n$ - $\mathrm{Si}<\mathrm{Er}>(4)$ после облучения $\gamma$-квантами ${ }^{60} \mathrm{Co}$. 
Исследовались также особенности радиационного дефектообразования в бескислородном кремнии, легированном Er или La. Измерения спектров DLTS контрольных образцов бескислородного кремния показали, что $\gamma$-облучение вводит в них, кроме $A$-центров, еще один характерный РД: $E$-центр с энергией ионизации $E_{c}-0.43$ эВ и сечением захвата электронов $\sigma_{n}=1.8 \times 10^{-15} \mathrm{~cm}^{-2}$ (кривые 3 и 4 на рисунке). Концентрация $E$-центров в этих образцах при дозе облучения $\Phi=8 \times 10^{17}$ кв/см ${ }^{2}$ составляет $5.6 \times 10^{13} \mathrm{~cm}^{-3}$, а концентрация $A$-центра $\approx 3.1 \times 10^{13} \mathrm{~cm}^{-3}$, т.е. примерно на порядок меньше концентрации $A$-центра в кислородном Si. Сопоставление спектров DLTS в облученных контрольных и легированных образцах показывает, что наличие примеси эрбия или лантана в объеме $\mathrm{Si}$ приводит к существенному уменьшению концентрации обоих уровней РД. Концентрации $A$-центров и $E$-центров в облученном $n$ - $\mathrm{Si}<\mathrm{Er}>$ или $n$ - $\mathrm{Si}<\mathrm{La}>$ почти на порядок меньше по сравнению с контрольными облученными образцами.

Таким образом, присутствие атомов эрбия или лантана в объеме кремния значительно снижает эффективность образования известных радиационных дефектов (комплексов вакансия-кислород и вакансия-фосфор). Можно предположить, что наблюдаемое уменьшение концентрации этих комплексов, скорее всего, обусловлено связыванием атомов кислорода с примесями редкоземельных элементов в комплексы, что наблюдалось ранее в работе [3], а также особенностями взаимодействия атомов $\mathrm{Er}$ и $\mathrm{La} \mathrm{c}$ точечными дефектами, вводимыми при гамма-облучении [6].

\section{ЛИТЕРАТУРА:}

1. В.В. Агеев, В.Н. Коковина, Н.Е. Приходько, Е.П. Трошина, Изв.Ленинград. электротех. института, 186, 51 (1976).

2. В.И. Шаховцов, В.Л. Шиндич. Радиационные эффекты в твердых телах (Киев, Наукова думка, 1977), с 88-102.

3. О.В. Александров, А.О. Захарьин, Н.А. Соболев, Ю.А. Николаев, ФТП 36, 3, 379 (2002).

4. С. Зайнабидинов, Д.Э. Назыров, М.И. Базарбаев. Электронная обработка материалов (Кишинев) В 4, 90 (2006).

5. Xiao Chuanyun, Jessica Blundell, Frank Hagelbergand, A. William, Jr. Lester, International Journal of Quantum Chemistry 96, Issue 4, 416 (2004).

6. В.В. Емцев, В.В. Емцев (мл.), Д.С. Полоскин, Н.А. Соболев, Е.И. Шек, Й. Михель, Л.С. Кимерлинг, ФТП 33, Вып. 6, 649 (1999).

7. G.L. Miller, D.V. Lang, L.C. Kimerling, Ann. Rev. Mater.Sci. 7, 377 (1977).

8. 8. Берман Л.С., Лебедев А.А. Емкостная спектроскопия глубоких центров в полупроводниках. Л., Наука, 1981, 170 с.

9. А.Т. Мамадалимов, А.А. Лебедев, Е.В. Астрова. Спектроскопия глубоких центров в полупроводниках (Ташкент, Университет, 1999).

10. Е.А. Татохин, А.В. Каданцев, А.Е. Бормонтов, В.Г.Задорожный, ФТП 44, 8, 1031 (2010).

11. В.С. Вавилов, Н.А. Ухин. Радиационные эффекты в полупроводниках и полупроводниковых приборах (Москва, Атомиздат, 1968). 